\title{
WORKING ENVIRONMENT SPECIALIST'S ROLE IN IMPROVEMENT OF SAFETY LEVEL IN ESTONIAN ENTERPRISES
}

\author{
Georgi Hrenov, Karin Reinhold, Piia Tint \\ Tallinn University of Technology, Estonia \\ ghrenov@mail.ru; karin.reinhold@ttu.ee,piia.tint@ttu.ee
}

\begin{abstract}
The active persons in safety and health activities in enterprises in Estonia are: the working environment specialists (WES), hired by the employer, and working environment representatives, selected by the workers. The number of small and medium-sized enterprises (SMEs) in Estonia is over 5000. Not all these enterprises can allow themselves the job with the designation of WES (or safety engineer). Therefore, these SMEs need very good descriptions of safety and health activities at the workplace and the information for the possibilities for improvement the safety level at these enterprises. The inspectors from the National Labour Inspectorate of Estonia never reach the SMEs unless an accident happens. In SMEs, the employer has to deal with the safety questions himself or these obligations are delegated to some of the top management's representative as an extra work. The main possibilities to influence on the safety level in the firm have the working environment specialists, as they are more educated and supported by the law in the work safety and health (OHS) area. The current paper is looking for the possibilities to raise the interest to the improvement of the safety level at enterprises through the strengthening of the knowledge of WES in OHS, particularly the knowledge on the main standard in OHS: OHSAS 18001. The safety level in 15 Estonian enterprises (metal, wood, construction, agriculture) was investigated through the MISHA method (based on OHSAS 18001). The latter version of the MISHA method was modified by the authors of the current paper (some of the important hazardous factors, like vibration etc. were added into the MISHA method). This modified MISHA questionnaire is an educational tool for the WES: this is the mode of learning through interviews. The influence of the implementation of OHSAS 18001 on real, formal and combined safety elements is determined. The connections were proved with statistics: factor analyses were carried out with Barlett's test, ANOVA and T-square test with Wilks' Lambda row.
\end{abstract}

Keywords: working environment specialist, safety engineer, real, formal and combined safety elements, improvement of safety level at enterprises.

\section{Introduction}

Health and safety management system can be characterized as a set of institutionalised interrelated and interacting strategic elements designed to establish and achieve occupational health and safety (OHS) goals and objectives [1]. In small and medium-sized enterprises, it is difficult to implement comprehensive safety management systems (SMSs) [2]. There is no knowledge and not enough workforce to deepen into the safety and health management details.

There are many methods suggested for evaluating the SMSs in the enterprise [3-5]. The conceptual model for OHS management system differentiates between its strategy and implementation [1]. The model suggests that the top management is responsible for strategically developing, articulating, recording, and communicating the strategic organizational OHS system. Based on a review of the strategic management literature, we identified three distinct theoretical constructs that can moderate or mediate the relationship between the organizational OHS system, its implementation and overall success: workgroup leadership, organizational values, and worker perceptions and interpretations of the OHS systems [1].

Thus, consistent with the strategic management literature [5], the OHS system may be studied within organizations as two district constructs: the strategically developed OHS system and OHS system implementation. The strategically developed OHS system represents the decreed and codified practice content designed by the strategic leaders and top managers for the organization. By Zohar and Tenne-Gazit [6]: “...assessment of OHS policies, procedures, and practices can be quite complex, requiring the establishment of differences between formally declared policies and procedures and their enforced counterparts. Formal policy is explicit, relating to overt statements and formal procedures, while enforced or enacted practices are tacit...".

The method for assessment of the safety management system in the enterprise, worked out by Kuusisto [7], is used by the authors of the current study in the previous investigations: the MISHA method that bases on the OHS standard OHSAS18001 [8-11]. Spear [12] refers to process indicators when describing key performance indicators such as safety audits, behavior-based safety, safety 
perception surveys, safety training, and corrective action measurements. Leading indicators are not so much the opposite of lagging indicators, but are instead a facet of safety likely to be present prior to an undesirable event [13; 14]. Podgorski [3] provides key performance indicators (KPIs) for measuring OHS management systems operational performance. The final set of KPIs contains 20 sub-sets (like OHS policy, evaluation and improvement of OHS training programmes, OHS goals and improvement plans, risk assessment process, management of change, management system audit, management review; actions for improvement: preventive and corrective actions, continual improvement etc.).

In the Estonian enterprises the manager is responsible for safety and health, but if there are resources and if the manager is educated in safety and health matters, then he hires a safety manager and gives him a comprehensive training in OHS. The safety mangers five top responsibilities are: 1) provide a workplace that is free from serious safety and health hazards; 2) monitor the workplace to ensure employees follow safety in manufacturing, 3) get the safety responsibilities done, 4) improve safety in manufacturing facilities with good signage, 5) note safety violations with clear tags [15].

The safety key elements in the current study are divided to real, formal and combined safety elements according to their content and possibilities to be in the improvement process [16]. The MISHA method has four areas: A) organization and administration, B) participation, C) work environment, D) follow-up (accidents etc.). Paas [16] divides the safety key elements in the MISHA method into three parts: formal safety elements, like safety documents, content of the policy $(R=0.895$, the correlation between the safety activities and the implementation or nonimplementation of OHSAS 18001), real safety elements, like top management commitment to the safety policy $(R=0.964)$ and combined safety elements, like participation in preparation of the safety policy $(R=0.888)$.

The working environment specialist (WES) is the key person in the enterprise in the occupational health and safety area and in the investigating the workers' health status. The aim of the study is to give the possibilities to small and medium-sized enterprises (SMEs) to improve the safety using the suitable questionnaires. The results of the questioning of WES (safety manager) are considered as the basic data for determination of the safety level.

\section{Materials and methods}

Fifteen Estonian companies (Table 1) were examined with the modified MISHA method, presented in [7]. Five (5) enterprises had implemented OHSAS 18001, three (3) enterprises were incorporated to the foreign firms and seven (6) enterprises had not implemented OHSAS 18001 neither incorporated to the foreign firms. For assessment of the MISHA questionnaire, the Likert scale ( 1 - poor, 2 - average, 3 - good, 4 - very good, 5 - excellent) was used. The Likert scale [17] is based on subjective assessments.

The MISHA questionnaire was modified taking into account some of the workplace hazards that were not included into the original MISHA questionnaire [7]. For example, vibration and electromagnetic fields influence on the workers was asked in the course of the interview [18]. The MISHA questionnaire was also shortened because very long questionnaires (lasting over 2 hours) are not appreciated by the answerers (work environment specialist). The interviews with the learning aims consist of the questionnaire that includes "whether" and "how" questions. In the original questionnaires compiled for the assessment of safety, activities at enterprises can be used as a tool for learning and obtaining more information on safety in companies. Learning is likely to be more effective when participants are actively involved in dialogue in which they are co-constructors of the meaning [19].

The questions from the MISHA questionnaire that concern the safety manager's activities, analysed in the current study, are as follows (numeration from [8]):

A1.1. Does the company has a written policy?

A1.3. Contents of the policy: a description of the safety tasks and responsibilities?

A1.4. Are the tasks and responsibilities assigned to the safety and health personnel?

A1.5. Have the safety and health personnel participated in preparation of the safety policy?

A1.6. Initial status review: current safety level, typical hazards in the company? 
A1.7. Does the policy list the following documents: work instructions, instructions for safety training, organization safety activity program?

A1.8. Revising the safety policy, who are responsible?

A1.9. Dissemination of the policy: is safety personnel involved?

A2.5. Safety manager: does the company have the safety manager? Has the safety manager received adequate safety training? Does the safety manager have adequate time and other resources for the safety activities?

A2.8. Does the company seek advice in resources to health and safety from safety personnel?

B1.1. Does the safety manager instruct the personnel?

B1.3. Has the safety manager established small groups with workers to discuss the safety matters?

B2.1. Has the safety manager arranged the hazards management system in the workplace?

B2.4. Does the safety manager arrange the safety campaigns?

B3.1. Safety training needs, are they determined to the personnel?

B3.4. Has the safety manager defined, which work permits are necessary, e.g. permit to do fire hazardous work?

C1.2. Does the safety manager inform the workers about the chemical hazards in the workplace?

C1.6. Has the safety manager provided the suitable clothing to the employees in extreme thermal conditions?

C1.7. Has the safety manager informed the workers about the accident hazards?

C1.8. Has the safety manager involved in cleaning of the plant area?

C1.9. Are the workers informed about the major accident hazards?

C2.3. Definition of the personnel responsibilities: are the persons responsible for health and safety trained for their responsibilities?

C3.1. Has the safety manager carried out the workplace hazard analysis?

C3.3. Tasks of the safety organization: does the safety organization participate in safety analysis?

D1.1. Does the company make statistics on accident rates, and summaries on accident causes?

D1.2. Accident investigation: are the near accidents investigated?

D2.2. Is the safety manager aware about the persons working under extreme mental stress?

The statistics used in the paper, involved IBM SPSS Statistics 22.0 and R.2.15.2. The following statistical methods were used: correlation, MANOVA, factor analysis, principal component method, independent T-test [20].

\section{Results of quantitative analysis}

The results of the quantitative analysis are given in Table 1 (column 6). The interviews by the MISHA method were carried out mainly with the safety manager, but if he (she) was not available, then with another employer's representative. The standard deviation (SD), if questioned three persons in the same enterprise (for example: manager, safety engineer and workers' representative) in the individual questions (like D2.2, C1.7 or B3.4) in the Likert scale $(0 \ldots 4)$ was $0.81 \ldots 2.81$; for the total score (max 100) SD was 2.01..2.45. So, the workers on different positions at the enterprise and with different meanings about safety and health gave rather similar answers assessing the safety and health level at health.

There are not much questions in the MISHA questionnaire that are directly showing the activities of the safety managers towards real, formal and combined safety key elements (Tables 2, 3, 4). Usually, if there is a safety manager in the company, he/she is responsible for all the activities in the safety area. If the safety management system is implemented, then the results of the safety activities in the company are reported continuously to the top manager.

Table 2 represents the results of the statistics between the connections of the safety manager's activities and formal safety elements. There is a good correlation between the formal safety elements and the written safety policy (in which composition the safety manager is certainly involved), $p=0.000$; between the contents of the policy: a description of the safety tasks and responsibilities (the safety manager involved in the distribution of the responsibilities in safety area), $p=0.000$; if OHSAS 18001 is implemented, then the tasks and responsibilities of safety and health personnel are clearly determined, $p=0.000$ (question A1.4. in Table 2). 
Characterization and results of the quantitative study using MISHA method $(N=15)$

\begin{tabular}{|c|c|c|c|c|c|}
\hline ID & $\begin{array}{l}\text { The activity } \\
\text { area }\end{array}$ & $\begin{array}{l}\text { Size, } \\
\text { employees }\end{array}$ & $\begin{array}{c}\text { OHSAS } \\
\text { company/corporated } \\
\text { company }\end{array}$ & The person interviewed & $\begin{array}{c}\text { Total } \\
\text { score } \\
(\mathbf{1 0 0 m a x}) \\
\end{array}$ \\
\hline 1 & 2 & 3 & 4 & $\mathbf{5}$ & 6 \\
\hline I & $\begin{array}{l}\text { Chemical } \\
\text { industry }\end{array}$ & $50-249$ & $+/-$ & $\begin{array}{c}\text { Management's representative, } 45 ; \\
\text { External auditor, } 34\end{array}$ & $\begin{array}{l}87 \\
78 \\
\end{array}$ \\
\hline II & $\begin{array}{l}\text { Chemical } \\
\text { industry }\end{array}$ & $50-249$ & $+/-$ & $\begin{array}{c}\text { Management's representative, } 55 \\
\text { External auditor, } 34\end{array}$ & $\begin{array}{l}88 \\
78 \\
\end{array}$ \\
\hline III & $\begin{array}{c}\text { Metal } \\
\text { industry }\end{array}$ & $50-249$ & $-/-$ & Safety manager, 64 & 62 \\
\hline IV & $\begin{array}{c}\text { Metal } \\
\text { industry }\end{array}$ & $>250$ & $-/+$ & Safety manager, 35 & 85 \\
\hline $\mathrm{V}$ & $\begin{array}{l}\text { Agriculture } \\
\text { farm } \\
\text { (milk } \\
\text { production) }\end{array}$ & $<50$ & $-/-$ & Employer, 50 & 46 \\
\hline VI & $\begin{array}{l}\text { Agriculture } \\
\text { farm (grain } \\
\text { production) }\end{array}$ & $<50$ & $-/-$ & Employer, 56 & 60 \\
\hline VII & Construction & $<50$ & $-1-$ & Active manager, 40 & 50 \\
\hline VIII & Transport & $50-249$ & $-1-$ & Personnel manager, 45 & 65 \\
\hline IX & $\begin{array}{l}\text { Plastic } \\
\text { industry }\end{array}$ & $50-249$ & $+/-$ & Safety manager, 62 & 78 \\
\hline $\mathrm{X}$ & Electronics & $>250$ & $-/+$ & Safety manager, 42 & 82 \\
\hline $\mathrm{XI}$ & Electronics & $>250$ & $+/-$ & Safety manager, 39 & 90 \\
\hline XII & $\begin{array}{c}\text { Food } \\
\text { industry }\end{array}$ & $>250$ & $-/+$ & Safety manager, 37 & 78 \\
\hline XIII & $\begin{array}{c}\text { Food } \\
\text { industry }\end{array}$ & $>250$ & $+/-$ & Safety chief specialist, 68 & 80 \\
\hline XIV & $\begin{array}{l}\text { Textile } \\
\text { industry }\end{array}$ & $>250$ & $-/-$ & Safety and health manager, 67 & 53 \\
\hline XV & $\begin{array}{l}\text { Printing } \\
\text { industry }\end{array}$ & $<50$ & $-/-$ & Production manager, 41 & 30 \\
\hline
\end{tabular}

The situation is another in the list of the existing safety-connected documents comparing the OHSAS 18001 implemented companies with the companies non-implemented OHSAS 18001: work instructions, instructions for safety training, organization safety activity program exists anyway, $p=0.241$. The revising of the safety policy is determined more clearly in OHSAS 18001 implemented companies compared with the non-implemented companies, $p=0.000$. The safety and health personnel have slightly better training possibilities and knowledge in OHS in OHSAS 18001implemented companies than in non-implemented companies $(\mathrm{C} 2.3, p=0.013)$. The accident investigation and statistics on it is usually made by the safety managers in the enterprises: these activities have much better quality in OHSAS 18001-implemented companies, $p=0.000$.

Table 3 represents the influence of OHSAS 18001 implementation on real safety elements in the enterprises. There is a good correlation between the safety manager's activities in the OHSAS 18001implemented companies and non-implemented companies: dissemination of the safety policy to the workers is carried out usually by the safety managers, $p=0.000$; the safety personnel is advising the top management about the necessity of allocate resources for safety improvements, $p=0.000$ (A2.8, Table 3); the safety manager instructs the personnel preliminary in OHS, $p=0.001$; the system for permission of workers to extreme work conditions is arranged, $p=0.004$.

In OHSAS 18001-implemented companies, the safety manager has arranged the hazard management system, $p=0.006$; arranges the safety campaigns, $p=0.006$; he (she) is involved in the maintenance of the working area, $p=0.002$. The influence of OHSAS 18001 implementation is less on the following safety manager's activities: the group discussion on safety matters (organized by the 
safety manager), the suitable clothing is usually provided by the safety manager for the work in hot and cold climate both, in OHSAS-implemented and non-implemented companies, the same on the information about the chemical hazards, $(p=0.120)$ and major accident hazards $(p=0.138)$.

Table 2

Influence of the implementation of OHSAS 18001 in enterprises on real safety elements

\begin{tabular}{|l|c|c|}
\multicolumn{1}{|c|}{ Formal safety element } & $\begin{array}{c}\text { Sum of squares (KMO } \\
\text { and Barlett's test) }\end{array}$ & $\begin{array}{c}\boldsymbol{p} \text { - } \\
\text { value }\end{array}$ \\
\hline A1.1. Does the company have a written policy? & 22.250 & 0.000 \\
\hline A1.3. Contents of the policy: a description of the safety tasks & 19.285 & 0.000 \\
\hline A1.4. Are the tasks assigned to the safety and health personnel? & 13.375 & 0.000 \\
\hline A1.7. Has safety manager made an initial OHS review in company? & 1.299 & 0.241 \\
\hline A1.8. Revising the safety policy, who are responsible? & 25.688 & 0.000 \\
\hline $\begin{array}{l}\text { C2.3. Definition of the personnel responsibilities: are the persons } \\
\text { responsible for health and safety trained for their responsibilities? }\end{array}$ & 4.576 & 0.013 \\
\hline $\begin{array}{l}\text { D1.1 Does the company make statistics on accident rates and summaries } \\
\text { on accident causes? }\end{array}$ & 21.000 & 0.000 \\
\hline
\end{tabular}

Table 3

Influence of the implementation of OHSAS 18001 in enterprises on real safety elements

\begin{tabular}{|l|c|c|}
\multicolumn{1}{|c|}{ Real safety element } & $\begin{array}{c}\text { Sum of squares } \\
\text { (KMO and Barlett's } \\
\text { test) }\end{array}$ & $\begin{array}{c}\text { p- } \\
\text { value }\end{array}$ \\
\hline A1.9. Dissemination of the policy: is safety personnel involved? & 21.007 & 0.000 \\
\hline $\begin{array}{l}\text { A2.8. Does the company seek advice in resources to health and safety } \\
\text { from safety personnel? }\end{array}$ & 22.688 & 0.000 \\
\hline B1.1. Does the safety manager instruct the personnel? & 5.672 & 0.001 \\
\hline $\begin{array}{l}\text { B1.3. Has the safety manager established small groups with workers to } \\
\text { discuss the safety matters? }\end{array}$ & 3.236 & 0.339 \\
\hline $\begin{array}{l}\text { B2.1. Has the safety manager arranged the hazard management system in } \\
\text { the workplace? }\end{array}$ & 2.896 & 0.006 \\
\hline B2.4. Does the safety manager arrange the safety campaigns? & 9.797 & 0.006 \\
\hline $\begin{array}{l}\text { B3.4. Has the safety manager defined which work permits are necessary } \\
\text { (e.g., permit to do fire hazardous work?) }\end{array}$ & 6.750 & 0.004 \\
\hline $\begin{array}{l}\text { C1.2. Does the safety manager inform the workers about the chemical } \\
\text { hazards in the workplace? }\end{array}$ & 2.410 & 0.120 \\
\hline $\begin{array}{l}\text { C1.6. Has the safety manager provided the suitable clothing to the } \\
\text { employees in extreme thermal conditions? }\end{array}$ & 1.451 & 0.139 \\
\hline C1.7. Has safety manager informed workers on accident hazards? & 2.714 & 0.017 \\
\hline C1.8. Has safety manager involved in cleaning of the plant area? & 4.500 & 0.002 \\
\hline C1.9. Are the workers informed about the major accident hazards? & 1.299 & 0.138 \\
\hline $\begin{array}{l}\text { D2.2. Is the safety manager aware about the persons working under } \\
\text { extreme mental stress? }\end{array}$ & 1.188 & 0.148 \\
\hline
\end{tabular}

Table 4 presents the statistically approved results of the influence of OHSAS 18001 to the combined safety elements (like participation in preparation of the safety policy, workplace hazard analysis etc.). The safety managers are taking part in preparation of the safety policy $(p=0.000)$, they give the initial safety status review $(p=0.001)$, safety training needs for the personnel are determined by the safety manager, workplace hazard analyses are organized by the safety manager $(p=0.000)$, near accidents are investigated in OHSAS-implemented companies $(p=0.007)$.

OHSAS 18001-implementation has less influence on safety training of the safety manager (they are trained also in OHSAS non-implemented companies, $p=0.220$ ), the safety manager takes part in the top management meetings also in non-implemented companies $(p=0.143)$. 
Table 4

Influence of the implementation of OHSAS 18001 in firms on combined safety elements

\begin{tabular}{|l|c|c|}
\hline \multicolumn{1}{|c|}{ Combined safety element } & $\begin{array}{c}\text { Sum of squares } \\
\text { (KMO and Barlett's } \\
\text { test) }\end{array}$ & $\boldsymbol{p}$-value \\
\hline A1.5. Participation in preparation of the safety policy & 21.500 & 0.000 \\
\hline A1.6. Initial status review & 13.375 & 0.001 \\
\hline A2.5. Safety training of the safety manager? & 1.194 & 0.220 \\
\hline B3.1. Safety training needs, are they determined to the personnel? & 2.854 & 0.004 \\
\hline C3.1. Workplace hazard analysis: has safety manager carried out? & 8.491 & 0.000 \\
\hline $\begin{array}{l}\text { C3.3. Does the safety manager take part in the discussions on the top } \\
\text { management level? }\end{array}$ & 1.965 & 0.143 \\
\hline D1.2. Accident investigation: are the near accidents investigated? & 4.125 & 0.007 \\
\hline
\end{tabular}

\section{Results of qualitative analysis}

In the qualitative analysis the enterprises with OHSAS 18001-implemented, corporated and nonimplemented firms are compared in safety and health activities area.

Case 1 - OHSAS-implemented enterprise $(N<50)$

OHSAS 18001 is implemented. The work for its implementation took altogether six months. There is a written safety policy, the management is committed to the safety matters. The implementation of OHSAS 18001 rises the competitiveness of the firm, it helps get more clients (abroad), the imago of the enterprise, the safety questions are discussed during the top management meetings, and it decreases the number of accidents and occupational and work-related diseases.

For example: "there was an evacuation training, which had not very good results exactly" (the words of the member of the work environment committee). After that, there was a meeting on this matter and the owner of the firm was actively taking part in the discussion that lasted for 2.5 hours.

Case 2 - corporated, OHSAS 18001 non-implemented enterprise $(N=450)$

A large enterprise, corporated with Swedish and Finnish firms. They have implemented their own inside the corporate applied standard (not OHSAS, but similar), the foreign auditors on safety matters visit the enterprise 3 times per year. The enterprise has the written safety policy.

The question to the safety manager: Has the safety policy made noted to every worker?

"Yes, they have read it and signed".

The near-accidents are not always registered and made known to the safety manager. Why not? The workers answered to the safety manager: "You will announce about the hazardous situations to the top management!" The workers' awareness of safety matters is inadequate.

Case 3 - OHSAS 18001 non-implemented enterprise $(N<50)$

The questions of the interviewer to the manager (who also has the WES responsibilities):

Has the enterprise a written safety policy?

"No, there is not, but we have the main principles for managing safety as much it is possible using the available resources".

Have you the work instructions (not safety instructions) for carrying out different jobs?

"No, we do not have. It is impossible to make a manual for every movement".

Have you carried out the risk assessment (RA) in the workplace and the action plan for reducing the risks?

"The risk assessment was carried out 6 years ago, but we have not yet had time to compile the action plan".

Good action: all the workers are insured. The workers are provided with the personal protective equipment. The primary safety requirements are fulfilled, if the worker goes to work in the morning, then he returns home in the evening without injuries.

Case 4-OHSAS 18001 non-implemented enterprise $(N<50)$

The questions to the active manager (who is also responsible for the safety matters): 
Is it difficult to stay competitive?

"It is difficult everywhere nowadays: The workers are not complaining".

The activities of the firm: they do not go to the safety training, but undergo medical examinations. The Labour inspectorate is continuously checking the firm. After the inspectorate's visit, the firm will be active in safety in the frames that are needed, but not more.

Have you carried out the risk assessment in your firm?

"At the beginning the demands of the labour inspector for making the RA were horrific (for example, there was a question: are the floors slippery?!), but then the labour inspector softened the demands and the firm carried out the RA".

The situation in the firms is very different as the people are all individuals, they want to show themselves good, but the resources for safety level improvements are different. The corporated and OHSAS-implemented firms have better possibilities to implement the safety policy and other documents, but the smaller firms also are eager to keep at least the minimum to care workers safe and healthy.

\section{Discussion}

Taking into account the results of the previous studies of the current papers authors [9;23], where the safety and health level on the enterprise measured with the MISHA method was carried out from the viewpoint of the working environment representative (WER) [9] and the employers [23], it could be said that the safety engineers have the best knowledge of the safety system.

The other key persons (WER, employer) are hesitant in some questions, concerning, for example, the safety policy expanding to the workers in the firm. The working environment specialist assesses the situation as it really is, but the WER and employer who have in the real work-life not so much connected to the safety questions, and also not have so much knowledge in safety, are overestimating the situation.

The MISHA method is not the only method for assessment and showing the improvement points in safety and health at enterprises [21;22]. By Arghami et al. [24], the safety climate questionnaire is built up on another basis than in the MISHA method. It contains seven (7) different factors: management commitment to safety and personnel collaboration: the influence of total safety level $(R=0.954)$, safety communication $(R=0.830)$, supportive environment $(R=0.793)$, work environment $(R=0.803)$, formal training $(R=0.774)$, priority of safety $(R=0.740)$, personal priorities and the need for safety $(R=0.547)$.

So, the results are comparable with the results in the current paper: the safety policy might be worked out very properly and on a high level, but the safety policy usually does not reach the personnel, from up to down, there are difficulties as in OHSAS-implemented as in non-implemented enterprises. One of the lowest scores $(R=0.431)$ is given to the question: "my line manager/supervisor does not always inform me of current concern and issues" [24].

In the investigation of the safety level by the authors of the current paper, the scores of correlation in different questions are even lower (real, formal and combined safety). The starting point for the research is also different (the comparison of the firms with implemented OHSAS18001 and nonimplemented ones). So, different questionnaires are useful for investigations in the safety level in enterprises and the result will be total.

\section{Conclusions}

1. OHSAS 18001 implementation helps improve the following formal safety elements where safety manager is involved: to write the safety policy, the description of tasks of the personnel in safety area, the responsibilities of the safety personnel are clearly determined.

2. OHSAS 18001 implementation helps improve the following real safety elements: dissemination of the safety policy, the safety personnel is advising the top management in safety and health questions, the safety manager instructs thoroughly the personnel in safety matters, the safety personnel is advising the top management how to allocate the resources. 
3. OHSAS 18001 implementation in the firm helps improve the following combined safety elements: safety manager compiles the initial safety review, the safety training needs of the personnel are determined, workplace hazard analyses are carried out.

4. The qualitative analysis shows the difference between the firms and safety knowledge of people responsible for safety.

\section{References}

1. Yorio P. L., Willmer D. R., Moore, S.M. Health and safety management systems through a multilevel and strategic management perspective: theoretical and empirical considerations. Safety Science, vol.72, 2015, pp. 221-238.

2. Arocena P., Nunez I. An empirical analysis of the effectiveness of occupational health and safety management systems in SMEs. International Small Business Journal, vol.28, 2010, pp. 398-419.

3. Podgorski D. Measuring operational performance of OHS management system - a demonstration of AHP-based selection of leading key performance indicators. Safety Science, vol.73, 2015, pp. 146-166.

4. Sinelnikov S., Inouye J., Kerper S. using leading indicators to measure occupational health and safety performance. Safety Science, vol.72, 2015, pp.240-248.

5. Becker B. E., Huselid M.A. Strategic human resources management: where do we do from here? Journal of Management, vol.32, no.6, 2006, pp. 898-925.

6. Zohar D., Tenne-Gazit O. Transformational leadership and group interaction as climate antecedents: a social network analysis. Journal of Applied Psychology, vol.93, no.4, 2008, pp. 744-757.

7. Kuusisto A. Safety management systems: audit tools and reliability of auditing [dissertation]. Tampere University of Technology, 2000.

8. Paas Õ. Development of the safety management system at enterprises [dissertation]. Tallinn University of Technology, 2015.

9. Hrenov G., Paas Õ., Tint P., Reinhold K. Workers' representation in OHS activities: example of Estonian industrial sector. Agronomy Research, vol.14, no.2, 2016, pp. 377-391.

10. Paas Õ., Reinhold K., Tint P. Estimation of safety performance by MISHA method and the benefits of OHSAS 18001 implementation in Estonian manufacturing industry. Agronomy Research, vol.13, no.3, 2015, pp. 792-809.

11. OHSAS 18001: 2007. Occupational health and safety management standard. British Standardization Board.

12. Spear J. Measuring safety and health performance: a review of commonly used performance indicators. J.E. Spear Consulting, pp. 1-6.

13. Hale A. Why safety performance indicators? Safety Science, vol.47, no.4, 2009, pp. 479-480.

14. Harms-Ringdahl L. Dimensions in safety indicators. Safety Science, vol.47, no.4, pp. 481-482.

15. Safety in manufacturing: learn the top 5 safety manager responsibilities \& never take safety for granted! In: Manufacturing safety, Chick Intrieri, 2013. [online] [1.03.2017]. Available at:

16. http://cerasis.com/2013/07/29/safety-in-manufacturing/

17. Paas Õ., Reinhold K., Tint P. OHSAS 18001 contribution to real and formal safety elements of safety management in manufacturing companies: results of statistical analysis. Agronomy Research, vol.13, no.5, 2015, pp. 1260-1274.

18. Likert R. A Technique for the measurement of attitudes. Archives of psychology, vol.140, 1932, pp. 1-55.

19. Paas Õ., Reinhold K., Tint, P. Learning through questioning in occupational health and safety. Zeszyty Naukowe Politechniki Poznanskiej. Organizacja I Zarzadzanie (Scientific Journals of Poznan University of Technology. Series of "Organization and Management"), no.67, 2015, pp. 69-85.

20. TEAL Center Fact Sheet No.12: Deeper learning through questioning. Teaching excellence in adult literacy, 2013. [online] [12.04.2015]. Available at: https://teal.ed.go/sites/default/files/Fact-Sheets/12_TEAL_Deeper_Learning_Qs_complete_5_10. pdf.

21. Field A. Discovering statistics using IBM statistics. Fourth edition. Sage Publications Ltd., http://www.uk.sagepub.com/field4e/main.htm 
22. Guldemund F. W. The use of questionnaires in safety culture research- and evaluation. Safety Science, vol.45, 2007, pp. 723-743.

23. Kines P., Lappalainen J., Mikkelsen K.L., Olsen E., Pousette A., Tharaldsen J. et al. Nordic safety climate questionnaire (NOSACQ-50): a new tool for diagnosing occupational safety climate. International Journal of Industrial Ergonomics, vol.21, 2011, pp. 634-646.

24. Hrenov G., Reinhold K., Tint, P. Employers' role in the improvement of safety level in Estonian enterprises. Environment, Technology, Resources (Periodical publication of the International Scientific and Practical Conference of Rezekne Academy of Technologies), 2017, 6 pp., in press.

25. Arghami S., Parkestani H. N. and Alimohammadi I. Reliability and validity of a safety climate questionnaire. Journal of Research in Health Sciences, vol. 14, no. 2, 2014, pp. 140-145. 